\title{
Horizontal variability of aerosol optical depth observed during the ARCTAS airborne experiment
}

\author{
Y. Shinozuka and J. Redemann \\ Bay Area Environmental Research Institute, Sonoma, California, USA \\ Received: 23 May 2011 - Published in Atmos. Chem. Phys. Discuss.: 31 May 2011 \\ Revised: 27 July 2011 - Accepted: 9 August 2011 - Published: 19 August 2011
}

\begin{abstract}
We present statistics on the horizontal variability of aerosol optical depth (AOD) directly measured from the NASA P-3 aircraft. Our measurements during two contrasting phases (in Alaska and Canada) of the ARCTAS mission arguably constrain the variability in most aerosol environments common over the globe. In the Canada phase, which features local emissions, $499 \mathrm{~nm}$ AOD has a median relative standard deviation $\left(\mathrm{std}_{\mathrm{rel}, \mathrm{med}}\right)$ of $19 \%$ and $9 \%$ and an autocorrelation $(r)$ of 0.37 and 0.71 over $20 \mathrm{~km}$ and $6 \mathrm{~km}$ horizontal segments, respectively. In the Alaska phase, which features long-range transport, the variability is considerably lower $\left(\operatorname{std}_{\mathrm{rel}}\right.$, med $=3 \%, r=0.92$ even over $\left.35.2 \mathrm{~km}\right)$. Compared to the magnitude of AOD, its wavelength dependence varies less in the Canada phase, more in the Alaska phase. We translate these findings from straight-line flight tracks into grid boxes and points, to help interpretation and design of satellite remote sensing, suborbital observations and transport modeling.
\end{abstract}

\section{Introduction}

The accuracy requirement for aerosol optical depth (AOD) retrievals by future satellite sensors has been set to 0.02 or $5 \%$ of AOD (whichever is greater) (e.g., Mishchenko et al., 2004), dictated by a wide range of applications. Even at this level of accuracy, AOD is a large contributor to uncertainties in estimates of direct aerosol radiative forcing of climate (Loeb and Su, 2010), and probably other applications as well. However, accuracy at the 0.02 level is difficult to achieve. Current satellite retrievals of AOD are subject to errors introduced by instrument calibration, treatment of surface boundary conditions, particle properties assumed in the

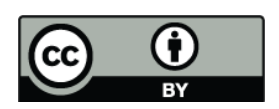

Correspondence to: Y. Shinozuka (yohei.shinozuka@nasa.gov) retrieval algorithm, and limitations caused by spatial sampling. For example, Kahn et al. (2007) show that differences in spatial sampling between MODIS and MISR can lead to differences in retrieved AOD between the two sensors far exceeding the accuracy requirements stated above. The same study concludes that variability in surface water conditions can create artificial variability in retrieved AOD greater than 0.02 , if ocean conditions are particularly unfavorable. Hence, variability in aerosol and surface properties has an impact not only on the accuracy of retrieved satellite AOD, but also on the testability of the AOD accuracy, because potential differences in satellite and suborbital observations have to be interpreted in the context of the actual natural variability of these parameters. Similar limitations apply to the validation of aerosol transport models, which provide aerosol information often at much coarser scales than satellite or suborbital observations that they are tested with. Finally, an accurate quantification of the spatial variability of aerosol properties would provide a means to assessing uncertainties involved in extrapolating suborbital observations to larger, data-sparse, region, as is frequently done with AERONET or airborne observations.

Anderson et al. (2003) analyzed the mesoscale variations of aerosol optical properties observed with groundbased, airborne and spaceborne instruments. Redemann et al. (2006) found that the spatial variability of AOD derived by the MODIS spaceborne sensors was larger than that indicated by collocated airborne measurements during the EVE campaign, mostly due to uncertainty in the MODIS retrievals. Shinozuka et al. (2004) estimated variations in column AOD to be $\sim 25 \%$ during the ACE 1 campaign based on airborne observations over 96 circular flight legs of about $60 \mathrm{~km}$ diameter as well as vertical profiles. Ichoku et al. (2002) compared standard deviations of the MODIS AOD with temporal variation of AERONET ground-based AOD measurements around the world for October 2002. Bréon et al. (2011) also compared these two sensors but for various

Published by Copernicus Publications on behalf of the European Geosciences Union. 
thresholds of the space and time window with 5 years of data, to help determine the strategy for evaluating the AOD retrievals from 4 other satellite sensors. While these studies focused on scales greater than $10 \mathrm{~km}$, those between 1 and $10 \mathrm{~km}$ are becoming more relevant, as satellite and model resolutions improve and more surface sites are established.

In this paper we quantify the realistic range of the variability in AOD and its wavelength dependence (Angstrom exponent) over horizontal distances of $1-35.2 \mathrm{~km}$. We take advantage of direct, precise, spatially dense and numerous airborne measurements made during the Arctic Research of the Composition of the Troposphere from Aircraft and Satellites (ARCTAS) experiment (Sect. 2.1). We isolate horizontal segments (Sect. 2.2) and calculate the standard deviation and autocorrelation of the measurements for them (Sect. 2.3), while noting sampling error (Sect. 2.4), instrument noise (Sect. 2.5) and relevant dimensions (Sect. 2.6). Based on the results, we discuss implications for the interpretation of existing data products and design of future projects (Sect. 3). Cloud and surface properties, though influential on satellite remote sensing, are excluded from our analysis. In situ data are left for future studies.

\section{Methods}

\subsection{Experiment}

ARCTAS took place primarily in Alaska, USA in March and April 2008 and Saskatchewan and Alberta, Canada in June and July 2008. The NASA P-3 aircraft mainly sampled Asian outflow in the Alaska phase and local forest fire smoke in the Canada phase. The aircraft traveled at $\sim 120 \mathrm{~m} \mathrm{~s}^{-1}$, covering $35.2 \mathrm{~km}$ in about $5 \mathrm{~min}$. The wind speed was $7 \pm 4 \mathrm{~m} \mathrm{~s}^{-1}$ and $8 \pm 4 \mathrm{~m} \mathrm{~s}^{-1}$ (mean \pm standard deviation) below $2 \mathrm{~km}$ altitude during the Alaska and Canada phase, respectively. Hence, the P-3 platform moved fast by comparison to advection and the measurements from the P-3 can usefully constrain the variability in atmospheric observables. An overview of the ARCTAS experiment is given by Jacob et al. (2010), and its meteorology is reviewed by Fuelberg et al. (2010).

AOD above the aircraft at 13 wavelengths between 354$2139 \mathrm{~nm}$ were measured with the 14-channel Ames Airborne Tracking Sunphotometer (AATS-14) under clear skies, averaged over $3 \mathrm{~s}$ and recorded every $4 \mathrm{~s}$. Shinozuka et al. (2011) describe data acquisition, screening, calibration, reduction and uncertainty analysis, as well as the vertical profiles, intercomparison and fine-mode fraction of observed AOD.

\subsection{Horizontal segments}

For this work we isolate horizontal legs in such a way that the standard deviation of GPS altitude within each leg is generally less than $10 \mathrm{~m}$. Measurements made above $2 \mathrm{~km}$ are excluded from our analysis because they are relatively sparse and rarely contain a significant fraction of full column AOD.
Each leg is separated into segments. A data point is allowed to enter more than one segment. Because our flights include roughly equal numbers of legs across and along plumes whenever such plumes were present, our data are not strongly biased toward either orientation.

\subsection{Standard deviation and autocorrelation}

Standard deviation and autocorrelation, the statistical parameters central to this work, are adopted from Anderson et al. (2003).

Standard deviation of data, $x_{1}, x_{2}, x_{3}, \ldots x_{N}$, within a segment can be estimated as

$\operatorname{std}_{0}=\sqrt{\frac{1}{N-1} \sum_{i}^{N}\left(x_{i}-m\right)^{2}}$.

Note the normalization by $N-1$ where $N$ is the number of samples. The sample mean, $m$, tends to be closer to the samples than the mean of the parent population is, particularly when $N$ is small. As a result $\operatorname{std}_{0}$ is, on average, $c$ times the standard deviation of the parent population where

$c=\sqrt{\frac{2}{N-1}} \frac{\Gamma\left(\frac{N}{2}\right)}{\Gamma\left(\frac{N-1}{2}\right)}$,

for a normal distribution of independent elements and $\Gamma$ is the gamma function. $c$ is $0.80,0.89,>0.97$ for $N=2,3$, $>10$, respectively. We divide the estimated standard deviation by this factor:

$\operatorname{std}=\operatorname{std}_{0} / c$.

Dividing the standard deviation by the mean yields relative standard deviation, $\operatorname{std}_{\text {rel }}$ :

$\operatorname{std}_{\text {rel }}=\operatorname{std} /|m| \times 100(\%)$.

For example, for a flight segment with a mean AOD of 0.57 and a standard deviation of 0.14 , the relative standard deviation is $25 \%$ (Fig. 1a). We only calculate std and $\operatorname{std}_{\text {rel }}$ for segments that have at least half of the potential maximum number of data points.

Figure $1 \mathrm{~b}$ shows std $\mathrm{rel}_{\text {rel }}$ of aD at $499 \mathrm{~nm}$ observed during the Canada phase. Its cumulative probability is plotted on the vertical axis. The fact that the curve goes through a probability of 0.5 (i.e., median) at $\operatorname{std}_{\mathrm{rel}}$ of $19 \%$ means that there is a $50 \%$ chance that the horizontal variability over a length of $20 \mathrm{~km}( \pm 0.2 \mathrm{~km})$ is $\leq 19 \%$. This figure also shows the 16th and 84th percentiles. The range between them would correspond to one standard deviation of the samples if the distribution were normal. 
a

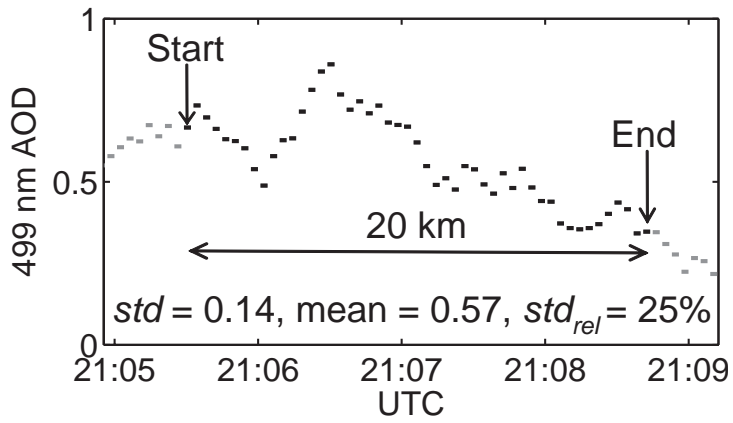

b

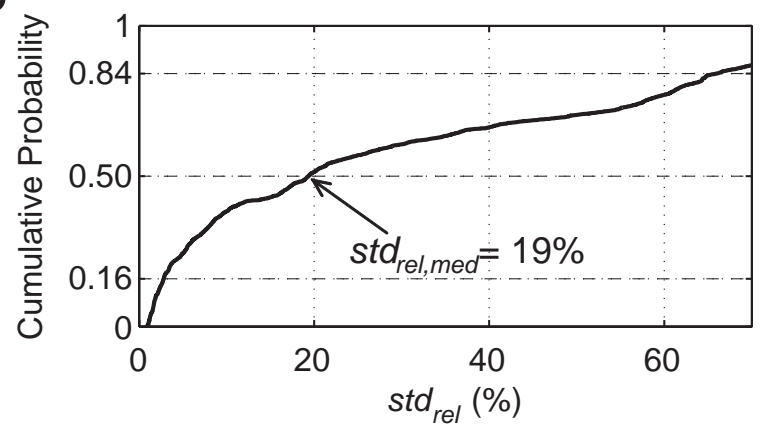

C

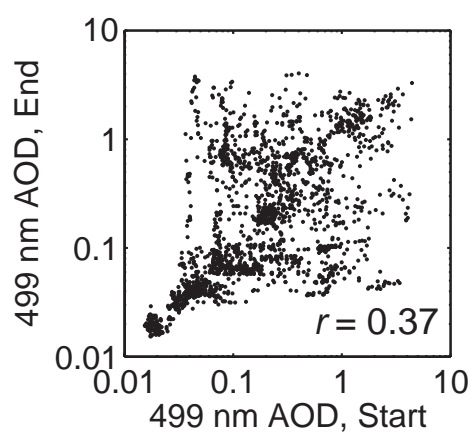

Fig. 1. (a) An example of $20-\mathrm{km}$ horizontal segments. The standard deviation (std) and mean (0.14 and 0.57 , respectively) of the $499 \mathrm{~nm}$ AOD measured during this segment (21:05:29-21:08:44 on 30 June 2008) yield a relative standard deviation $\left(\mathrm{std}_{\mathrm{rel}}\right)$ of $25 \%$. (b) Cumulative probability of $\mathrm{std}_{\mathrm{rel}}$ for the Canada phase. Included are 2565 of the $20-\mathrm{km}$ segments that have at least 20 valid data points. Its median value ( $\left(\mathrm{std}_{\mathrm{rel}, \mathrm{med}}\right)$ is $19 \%$. (c) The 2735 pairs of $499 \mathrm{~nm}$ AOD, each with a $20 \mathrm{~km}$ interval, in the Canada phase. Although this panel has logarithmic scales to include the wide range of observed AOD, autocorrelation $(r=0.37)$ is calculated on a linear basis.

Autocorrelation is the correlation coefficient among all data pairs $x_{j}$ and $x_{j+k}$ that exist at a separation, or lag, of $k$. That is,

$r=\frac{\sum_{j}^{N}\left[\left(x_{j}-m_{+k}\right)\left(x_{j+k}-m_{-k}\right)\right]}{(N-1) s t d_{+k} s t d_{-k}}$, where $k$ indicates the spatial lag (or distance), $m_{+k}$ and std ${ }_{+k}$ denote the mean and standard deviation, respectively, of all data points that are located a distance of $+k$ away from another data point, and $m_{-k}$ and $\operatorname{std}_{-k}$ are the corresponding quantities for data points located a distance of $-k$ away from another data point (Redemann et al., 2006; Anderson et al., 2003).

Figure 1c shows pairs of $499 \mathrm{~nm}$ AOD measured $20 \mathrm{~km}$ $( \pm 0.2 \mathrm{~km})$ away from each other in the Canada phase. The correlation coefficient, $r$, is 0.37 . This is the autocorrelation for $20 \mathrm{~km}$.

\subsection{Sampling error}

Calculated for a finite number (thousands for most distances; see Supplement Table 2) of segments, the median standard deviations and autocorrelation are subject to a sampling error. We approximate it by calculating how different these parameters would be if the sample size were even smaller. Specifically, we derive them for half as many data points as the entire collection, either starting or ending at a randomly chosen point of time. After repeating this 1000 times, the range that contains $68 \%$ of the results is given as the error bar. Note this is independent of the correction with Eq. (3) applied to std within each segment.

\subsection{Instrument noise}

$\operatorname{std}_{\text {med }}$, std $\mathrm{sel}_{\text {,med }}$ and $r$ accurately account for the horizontal variability of properties only when instrument noise, also folded into these statistical parameters, is negligible or isolated. (Systematic error hardly matters.) The best indication of instrument noise is in the transition from one measurement to the next, assuming that the noise is most pronounced at short frequencies.

$\mathrm{std}_{\text {rel, med }}$ for consecutive pairs of the $499 \mathrm{~nm}$ AOD measurements in the Alaska phase is $0.3 \%$. std rel, med $_{\text {for most }}$ lengths $(1-35.2 \mathrm{~km})$ in both phases is significantly greater, as we see in Sect. 3.1. This indicates that they are hardly influenced by the instrument noise and are a fairly good indicator of the ambient variability in this context.

In the Canada phase, $\operatorname{std}_{\text {rel,med }}$ for consecutive pairs of $499 \mathrm{~nm}$ AOD measurements is $2 \%$. This is mostly attributable to enhanced ambient aerosol heterogeneity during two AATS measurements encompassing $\sim 0.7 \mathrm{~km}$. We have no reason to believe that the instrument noise per true AOD increased from the spring phase to the summer.

Autocorrelation is subject to a similarly small impact of the instrument noise. $r$ for consecutive pairs (with the midpoints of measurements $\sim 0.4 \mathrm{~km}$ away from each other) of AOD for the Alaska phase is $>0.994$ for all wavelengths. This is only possible with a negligible AATS instrument noise. 


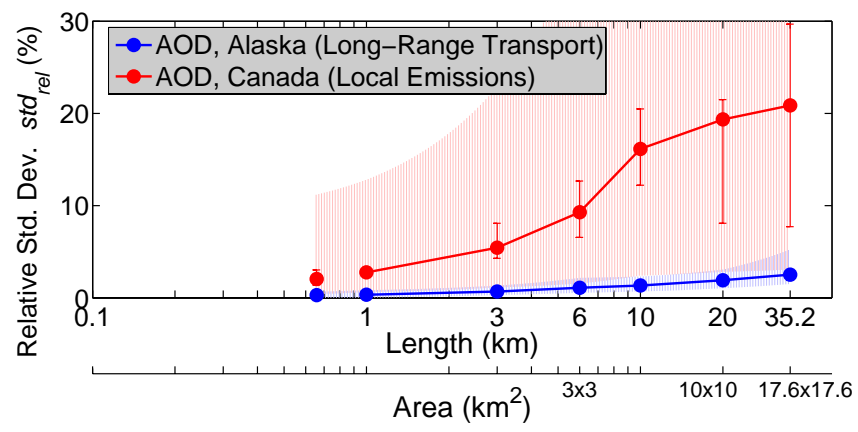

Fig. 2. Median relative standard deviation $\left(\operatorname{std}_{\text {rel,med }}\right)$ of $499 \mathrm{~nm}$ AOD in the Alaska (blue curve) and Canada (red curve) phases. The shades indicate the range between the 16th and 84th percentiles. Numbers are given in Table 1. Data points at $0.66 \mathrm{~km}$ are for the consecutive pairs. Of these, the one from the Alaska phase gives the least exaggerated estimate of impact of the instrument noise for both phases (see Sect. 2.5). Other data points are for horizontal segments of the stated length $\pm 0.2 \mathrm{~km}$. The second horizontal axis indicates the area that accommodates the same standard deviation as the corresponding length (see Sect. 2.6). Vertical bars indicate a measure of sampling error (see Sect. 2.4). Some of them are too short to be discernible.

Note that for both the standard deviations and autocorrelation, the precision presented here is likely higher than what it would be had our AOD measurements been smoothed over $<3$ s.

\subsection{Conversion from flight track to grid cell}

Horizontal scale is usually defined in terms of either length (e.g., Anderson et al., 2003; Redemann et al., 2006) or area (e.g., Kahn and Teixeira, 2009). The distinction between these two dimensions is important when comparing variability data, as properties of atmospheric constituents generally vary more in a square than along one of its sides.

We propose, as a guideline for our analysis (Sect. 3.3), that $\mathrm{std}_{\text {med }}$ and $\mathrm{std}_{\mathrm{rel} \text {,med }}$ derived for $35.2 \mathrm{~km}, 20 \mathrm{~km}$ and $6 \mathrm{~km}$ flight segments equally apply to $17.6 \times 17.6 \mathrm{~km}^{2}$, $10 \times 10 \mathrm{~km}^{2}$ and $3 \times 3 \mathrm{~km}^{2}$ areas, respectively. To develop this guideline, we considered two distances: one between two random points in a square whose sides have length $a$, and the other between two random points on a line of length $a$. The probability density function for the ratio of these distances is near log-normal and has a geometric mean of $\exp (\pi / 3+1 / 3 x \ln 2-7 / 12)$ or $2.0035 \ldots$ (see Supplement for a derivation of this as well as verification with a Monte Carlo simulation). We interpret this as a sign that an $a \times a$ square and a $2 a$-long line accommodate an identical degree of variability on average. We note, however, that the factor would be closer to 1 had the legs used to calculate the variability been aligned with the direction of advection.

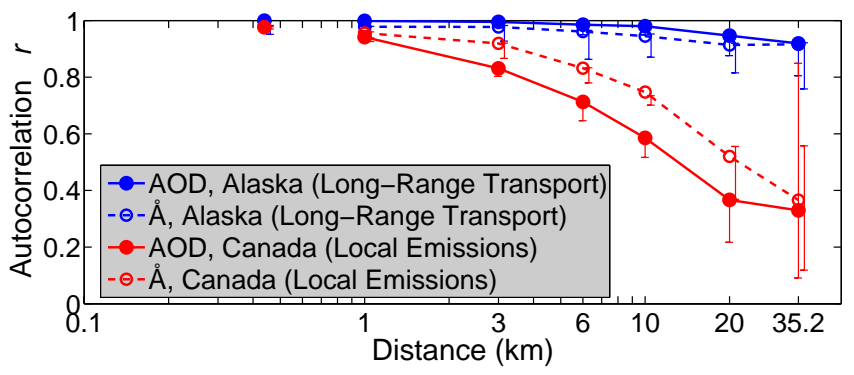

Fig. 3. Autocorrelation ( $r$ ) of $499 \mathrm{~nm}$ AOD (solid curves) and Angstrom exponent ( $\AA$, dashed) in the Alaska (blue) and Canada (red) phases. Numbers are given in Table 1. Data points at $0.44 \mathrm{~km}$ are for the consecutive pairs. Of these, the one from the Alaska phase gives the least exaggerated estimate of impact of the instrument noise for both phases (see Sect. 2.5). Other data points are for data pairs each of which has a gap of the stated distance $\pm 0.2 \mathrm{~km}$. Vertical bars indicate a measure of sampling error (see Sect. 2.4). Some of them are too short to be discernible. The bars for Angstrom exponent are intentionally shifted to the right for clarity.

\section{Results and discussion}

\subsection{Dependence on scale and aerosol environment}

std $_{\text {rel,med }}$ for $499 \mathrm{~nm}$ AOD is shown on the vertical axis in Fig. 2. It is $19 \%$ for $20 \mathrm{~km}$ segments in the Canada phase, as mentioned in Sect. 2.3 (Fig. 1b). $r$ for $499 \mathrm{~nm}$ AOD is shown on the vertical axis in Fig. 3. It is 0.37 for $20 \mathrm{~km}$ segments in the Canada phase, as mentioned in Sect. 2.3 (Fig. 1c). The same calculations for $1-35.2 \mathrm{~km}$ segments reveal a rapid increase in the variability (i.e., an increase in $\mathrm{std}_{\mathrm{rel}}$,med and a decrease in $r$ ) with distance. Recall that the Canada phase mainly sampled smoke, often right above forest fires (see the right panel of Fig. 4 for an example), with only a few airmasses after long-range transport. In contrast, the Alaska phase studied airmasses arriving from Asia after significant spatial mixing (the left panel of Fig. 4), and yielded much lower $\operatorname{std}_{\text {rel,med }}$ and higher $r$. They are $3 \%$ and 0.92 even for $35.2 \mathrm{~km}$ segments, with only small changes with distance. All these statistics from horizontal legs below $2 \mathrm{~km}$ are given in Table 1.

The parameters plotted in Figs. 2 and 3 all contain some instrument noise and sampling error, as discussed above. std $_{\text {rel,med }}$ and $r$ values for consecutive pairs in the Alaska phase, plotted at $0.7 \mathrm{~km}$ and $0.4 \mathrm{~km}$, respectively, indicate that the instrument noise is a negligible part of the variability observed in both phases, except for $<\sim 3 \mathrm{~km}$ in the Alaska phase (see Sect. 2.5 for details). The vertical bars represent the sampling error explained in Sect. 2.4. 
Table 1. Variability in the $499 \mathrm{~nm}$ AOD and Angstrom exponent for the Alaska (AL) and Canada (CAN) phases.

\begin{tabular}{|c|c|c|c|c|c|c|c|c|}
\hline & & cons. & $1 \mathrm{~km}$ & $3 \mathrm{~km}$ & $6 \mathrm{~km}$ & $10 \mathrm{~km}$ & $20 \mathrm{~km}$ & $35.2 \mathrm{~km}$ \\
\hline \multicolumn{9}{|l|}{ AOD } \\
\hline \multirow{4}{*}{$\begin{array}{l}\text { std }_{\text {rel,med }} \\
(16-84 \\
\text { percentiles })\end{array}$} & $\mathrm{AL}$ & $0.3 \%$ & $0.3 \%$ & $0.7 \%$ & $1.1 \%$ & $1.3 \%$ & $1.9 \%$ & $2.5 \%$ \\
\hline & & $(0.0 \%-0.7 \%)$ & $(0.0 \%-0.8 \%)$ & $(0.3 \%-1.3 \%)$ & $(0.5 \%-2.2 \%)$ & $(0.7 \%-2.3 \%)$ & $(1.0 \%-3.1 \%)$ & $(1.5 \%-5.3 \%)$ \\
\hline & CAN & $2.1 \%$ & $2.8 \%$ & $5.4 \%$ & $9.3 \%$ & $16.2 \%$ & $19.3 \%$ & $20.9 \%$ \\
\hline & & $(0.4 \%-11.2 \%)$ & $(0.6 \%-12.8 \%)$ & $(1.1 \%-22.8 \%)$ & $(1.5 \%-37.4 \%)$ & $(2.4 \%-50.9 \%)$ & $(2.8 \%-66.0 \%)$ & $(3.1 \%-83.3 \%)$ \\
\hline \multirow[t]{2}{*}{$r$} & $\mathrm{AL}$ & 1.00 & 1.00 & 1.00 & 0.99 & 0.98 & 0.95 & 0.92 \\
\hline & CAN & 0.98 & 0.94 & 0.83 & 0.71 & 0.59 & 0.37 & 0.33 \\
\hline \multicolumn{9}{|c|}{ Angstrom exponent } \\
\hline \multirow{4}{*}{$\begin{array}{l}\operatorname{std}_{\text {med }} \\
(16-84 \\
\text { percentiles })\end{array}$} & $\mathrm{AL}$ & 0.012 & 0.021 & 0.034 & 0.041 & 0.038 & 0.042 & 0.045 \\
\hline & & $(0.0-0.1)$ & $(0.0-0.1)$ & $(0.0-0.1)$ & $(0.0-0.1)$ & $(0.0-0.1)$ & $(0.0-0.1)$ & $(0.0-0.1)$ \\
\hline & CAN & 0.008 & 0.011 & 0.019 & 0.037 & 0.062 & 0.091 & 0.077 \\
\hline & & $(0.0-0.0)$ & $(0.0-0.0)$ & $(0.0-0.1)$ & $(0.0-0.1)$ & $(0.0-0.2)$ & $(0.0-0.2)$ & $(0.0-0.3)$ \\
\hline \multirow[t]{2}{*}{$r$} & $\mathrm{AL}$ & 0.98 & 0.98 & 0.98 & 0.96 & 0.94 & 0.91 & 0.92 \\
\hline & CAN & 0.98 & 0.96 & 0.92 & 0.83 & 0.75 & 0.52 & 0.37 \\
\hline
\end{tabular}

cons. is consecutive pairs. Whereas std ${ }_{\text {rel, med }}$ for AOD is given in percentage, $\operatorname{std}_{\text {med }}$ for Angstrom exponent is pertinent to the absolute values of Angstrom exponent and has no unit. Data for other wavelengths are given in Supplement Table 1. The number of samples is in Supplement Table 2.

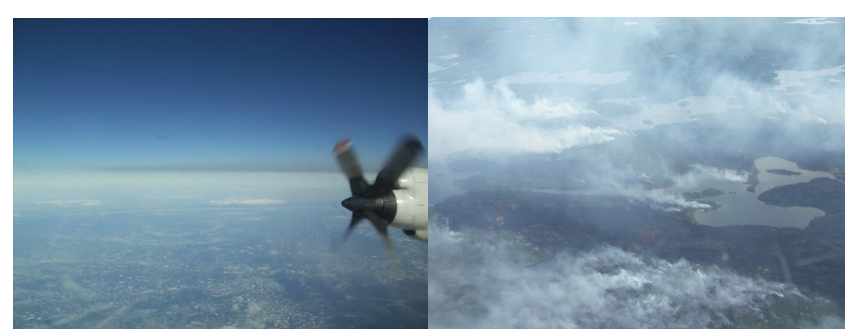

Fig. 4. (left) An example of a homogeneous aerosol layer photographed from the P-3 aircraft during the Alaska phase. Courtesy of Cameron $\mathrm{M}^{\mathrm{c}}$ Naughton. (right) An example of smoke sampled right above forest fires during the Canada phase.

\subsection{Comparison between AOD and Angstrom Exponent}

Unlike standard deviation, correlation can be readily compared between different properties. The dashed curves in Fig. 3 are for Angstrom exponent, AOD's wavelength dependence derived at $499 \mathrm{~nm}$ from second-order polynomial fits over the entire AATS-14 wavelengths (see Shinozuka et al. 2011 for an assessment of the Angstrom exponent).

The autocorrelation for Angstrom exponent is not as different between the two phases as that for the AOD at a single wavelength. $r(20 \mathrm{~km})$ is 0.52 for the Angstrom exponent during the Canada phase, greater than 0.37 for the $499 \mathrm{~nm}$ AOD. This is consistent with the fact that the wavelength dependence does not necessarily change with the dilution of air. The fact that the Angstrom exponent is already high (2.0-2.4) and cannot go much higher may be another reason why it is relatively stable. In the Alaska phase, $r$ for the Angstrom exponent is only slightly smaller (0.91) than for the $499 \mathrm{~nm}$ AOD (0.95). This difference is insignificant, given the estimated range of sampling error (vertical bars, see Sect. 2.4) and the estimated impact of instrument noise (plotted at $0.4 \mathrm{~km}$, see Sect. 2.5).

The results suggest that different strategies may be useful for observing the magnitude and the wavelength dependence of AOD. For example, in heterogeneous environments similar to the Canada phase, AOD may be monitored with a correlation coefficient of $>0.8$ from a sunphotometer station within $3 \mathrm{~km}$ of the point of interest. The Angstrom exponent may be monitored with the same level of correlation $6 \mathrm{~km}$ away. Our statistics thus aid in determining the spatial resolution required of a monitoring mission (e.g., Distributed Regional Aerosol Gridded Observation Networks, DRAGON) in order to achieve a specific level of correlation. The same holds true for satellite AOD validation from surface stations kilometers out of the swath, an exercise deemed necessary for satellite sensors with a narrow swath.

In an effort to make the results from the two ARCTAS phases more comparable with each other, we analyzed a subset of the Canada data with the $499 \mathrm{~nm}$ AOD between 0.05 and 0.17 , the range in which $95 \%$ of the Alaska data fall. We found that essentially all trends remain evident for the Canada phase when considering only the low AOD subset.

\subsection{Applications of quantitative assessments of AOD variability}

In this section, we discuss a few ideas regarding the quantitative use of our AOD variability assessments. As described in Sect. 2.6, we assume that the spatial variability in a square area equals the variability along a straight line twice as long as one side of the square. An obvious first application of the AOD variability statistics derived here is to help assess the consistency of coincident AOD measurements between 
MODIS and AERONET. The MODIS AOD retrieved for a $10 \times 10 \mathrm{~km}^{2}$ pixel does not have to be the same as the AOD at an AERONET ground site, which is a point in the grid cell. We often fail to ascertain how much of the observed AOD difference is attributable to the spatial scale difference, unable to confine errors intrinsic to instruments and algorithms. According to our statistics (Fig. 2), the AOD difference is likely within $19 \%$, in an atmosphere to which the Canada phase's median values and our guideline scale conversion apply. This high variability encourages averaging of AERONET data over time for the comparison (e.g., Ichoku et al., 2002), perhaps taking advection into account. In a homogeneous aerosol environment similar to the Alaska phase, the ambient variability is only $2 \%$. The collocation error associated with a one-time AERONET measurement should typically be negligible compared with the MODIS accuracy $( \pm 0.05 \pm 0.15 \times$ AOD over land $)$.

What if the MODIS grid cell was smaller, as planned for the future Collection 6 retrievals? For a $3 \times 3 \mathrm{~km}^{2}$ pixel (see the results for $6 \mathrm{~km}$ segments) in the extremely heterogeneous air, the horizontal variability likely explains $9 \%$, 10 percentage points lower than for the $10 \times 10 \mathrm{~km}^{2}$ pixel. On the other hand, in the more homogeneous environment, the difference is only 1 percentage point $\left(\mathrm{std}_{\mathrm{rel}}\right.$,med decreases from $2 \%$ to $1 \%$ ). Reducing the grid box might only deteriorate the satellite retrieval due to poorer surface characterization, cloud screening and signal-to-noise ratio. Our statistics thus help consider the trade-off between resolution and accuracy. This is applicable for other satellites such as MISR with $17.6 \times 17.6 \mathrm{~km}^{2}$ pixels, and may indeed be more important for satellite retrievals that combine radiance measurements with different footprints for a single aerosol retrieval (e.g., multi-angle measurements whose spatial domains are a function of viewing angle). Similar assessments can be made for grid-based transport models (e.g., Qian et al., 2010) on the trade-off between computer time and accuracy.

Note that the AATS measurements used to create the AOD variability statistics here each represent $3 \mathrm{~s}$, in which our aircraft typically traveled $\sim 0.3 \mathrm{~km}$ (see Sect. 2.5 for related discussions). Measurements from a geographical point (e.g., AERONET sites) may represent a greater horizontal scale and hence a smaller deviation from the regional average, depending on the length of measurement time period and wind speed. Also note that our statistics predict the frequency distribution of $\operatorname{std}_{\text {rel }}$ but not $\mathrm{std}_{\text {rel }}$ for individual cases. The variability for individual cases can far exceed the median (50th percentile) values. This is indicated by the wide range of std $_{\text {rel }}$ between the 16th and 84th percentiles (e.g., 3-66\% for the $20 \mathrm{~km}$ segments in the Canada phase).

Horizontal variability also obscures the correspondence between particulate mass measured at a ground site and satellite-derived AOD. Wang and Christopher (2003) demonstrated that linear correlation coefficient $(R)$ between a satellite-derived AOT and ground-based measurement of $\mathrm{PM}_{2.5}$ was 0.70 during their observation in Jefferson County,
Alabama in 2002. Horizontal variability of AOT within the satellite grid box can likely explain a fraction of the variation in the observed AOT-to-mass relationship. If this effect was estimated, other effects associated with size distribution, density and instrument and retrieval errors could be confined. In fact, another study (Shinozuka et al., 2007) excluded the effect of horizontal variability by estimating particle mass and AOD from a single platform during the INTEX-North America campaign, and found a higher correlation between them $\left(R^{2}=0.77\right)$ for the majority of the data. Such considerations on horizontal variability are essential for assessing the feasibility of satellite-based air quality monitoring (Hidy et al., 2009).

There is another way to look at $\operatorname{std}_{\text {rel,med }}$ It is nearly cut in half going from $20 \mathrm{~km}$ to $6 \mathrm{~km}$ in both phases. More generally, the relative changes with the scale are similar between the two phases. One way to express the relative changes is to fit a curve

$$
\log _{10}\left(\text { std }_{\text {rel, med }}\right)=a \times \log _{10}(\text { length })+\log _{10} b
$$

where length is given in $\mathrm{km}$. $a$ is 0.6 for $499 \mathrm{~nm}$ AOD for both phases. ( $b$ indicates the fitted $s_{\text {rel, med }}$ value at $1 \mathrm{~km}$. As we have seen in Fig. 2, this is wildly different between the phases: $0.4 \%$ in the Alaska phase, $3.0 \%$ in the Canada phase.)

\section{Conclusions}

Aerosol mixes spatially during transport. The degree of mixing is known to dramatically differ between minutes after the emission and a week later. The present work focuses on airmasses at these two stages of evolution, and quantifies the variability observed directly from the NASA P-3 aircraft. We believe our data from the Alaska and Canada phases of ARCTAS can help assess other aerosol environments common over the globe, because the horizontal variability in most of them arguably falls between these two extremes. Only a handful of environments can conceivably be more homogeneous than the Alaska phase (e.g., long range transport to a dry continental air) or more heterogeneous than the Canada phase (e.g., aircraft/ship emissions or volcanic eruptions into a humid marine boundary layer). Even if greater extremes in variability exist in other environments, the ARCTAS data provide a useful quantification for two very different yet common types of environment.

Over a $20 \mathrm{~km}$ length (and, by extension, a $10 \times 10 \mathrm{~km}^{2}$ area), $499 \mathrm{~nm}$ AOD typically varies by $19 \%\left(\operatorname{std}_{\text {rel,med }}\right)$ in an extremely heterogeneous airmass subject to fresh local emissions, and by $2 \%$ in an extremely homogeneous one after long-range transport. To employ a different expression of variability, the AOD is much less correlated across $20 \mathrm{~km}$ in the heterogeneous airmass $(r=0.37)$ than in the homogeneous one (0.95). The variation in the Angstrom exponent contrasts less sharply between the two extreme environments. 
The horizontal variability tabulated in this work can be used to test retrieved and modeled data products, determine the applicability of surface based measurements, and plan new missions. Examples we have mentioned are AOD comparison between MODIS and AERONET, satellite-based $\mathrm{PM}_{2.5}$ monitoring and optimizing distances between groundbased sunphotometers. Pursuit of other ways to use our results is encouraged.

\section{Supplementary material related to this article is available online at: http://www.atmos-chem-phys.net/11/8489/2011/ acp-11-8489-2011-supplement.zip.}

Acknowledgements. We thank Phil Russell, John Livingston, Meloë Kacenelenbogen, Brian Kahn, Lorraine Remer, Rich Kleidman, Tony Clarke, Steve Howell and Ralph Kahn for valuable input. Funding through NASA grants NNX08AF88G and NNX10AN60G (Program manager, H. Maring) is gratefully acknowledged.

Edited by: P. Quinn

\section{References}

Anderson, T. L., Charlson, R. J., Winker, D. M., Ogren, J. A., and Holmen, K.: Mesoscale variations of tropospheric aerosols, J. Atmos. Sci., 60, 119-136, 2003.

Bréon, F. M., Vermeulen, A., and Descloitres, J., An evaluation of satellite aerosol products against sunphotometer measurements, Remote Sens. Environ., in press, 2011.

Fuelberg, H. E., Harrigan, D. L., and Sessions, W.: A meteorological overview of the ARCTAS 2008 mission, Atmos. Chem. Phys., 10, 817-842, doi:10.5194/acp-10-817-2010, 2010.

Hidy, G. M., Brook, J. R., Chow, J. C., Green, M., Husar, R. B., Lee, C., Scheffe, R. D., Swanson, A., and Watson, J. G.: Remote sensing of particulate pollution from space: have we reached the promised land?, J. Air Waste Manage., 59, 1130-1139, 2009.

Ichoku, C., Chu, D. A., Mattoo, S., Kaufman, Y. J., Remer, L. A., Tanré, D., Slutsker, I., and Holben, B. N.: A spatio-temporal approach for global validation and analysis of MODIS aerosol products, Geophys. Res. Lett., 29, 8006, doi:8010.1029/2001GL013206, 2002.

Jacob, D. J., Crawford, J. H., Maring, H., Clarke, A. D., Dibb, J. E., Emmons, L. K., Ferrare, R. A., Hostetler, C. A., Russell, P. B., Singh, H. B., Thompson, A. M., Shaw, G. E., McCauley, E., Pederson, J. R., and Fisher, J. A.: The Arctic Research of the Composition of the Troposphere from Aircraft and Satellites (ARCTAS) mission: design, execution, and first results, Atmos. Chem. Phys., 10, 5191-5212, doi:10.5194/acp-10-5191-2010, 2010.
Kahn, B. H. and Teixeira, J.: A Global Climatology of Temperature and Water Vapor Variance Scaling from the Atmospheric Infrared Sounder, J. Climate, 22, 5558-5576, 2009.

Kahn, R. A., Garay, M. J., Nelson, D. L., Yau, K. K., Bull, M. A., Gaitley, B. J., Martonchik, J. V., and Levy, R. C.: Satellite-derived aerosol optical depth over dark water from MISR and MODIS: Comparisons with AERONET and implications for climatological studies, J. Geophys. Res., 112, D18205, doi:10.1029/2006JD008175, 2007.

Loeb, N. G. and Su, W.: Direct Aerosol Radiative Forcing Uncertainty Based on a Radiative Perturbation Analysis, J. Climate, 23, 5288-5293, 2010.

Mishchenko, M. I., Cairns, B., Hansen, J. E., Travis, L. D., Burg, R., Kaufman, Y. J., Vanderlei Martins, J., and Shettle, E. P.: Monitoring of aerosol forcing of climate from space: Analysis of measurement requirements, J. Quant. Spectrosc. Ra., 88, 149-161, doi:10.1016/j.jqsrt.2004.03.030, 2004.

Qian, Y., Gustafson Jr., W. I., and Fast, J. D.: An investigation of the sub-grid variability of trace gases and aerosols for global climate modeling, Atmos. Chem. Phys., 10, 6917-6946, doi:10.5194/acp-10-6917-2010, 2010.

Redemann, J., Zhang, Q., Schmid, B., Russell, P. B., Livingston, J. M., Jonsson, H., and Remer, L. A.: Assessment of MODISderived visible and near-IR aerosol optical properties and their spatial variability in the presence of mineral dust, Geophys. Res. Lett., 33, L18814, doi:18810.11029/12006GL026626, 2006.

Shinozuka, Y., Clarke, A. D., Howell, S. G., Kapustin, V. N., and Huebert, B. J.: Sea-salt vertical profiles over the Southern and tropical Pacific oceans: Microphysics, optical properties, spatial variability, and variations with wind speed, J. Geophys. Res., 109, D24201, doi:24210.21029/22004JD004975, 2004.

Shinozuka, Y., Clarke, A. D., Howell, S. G., Kapustin, V. N., McNaughton, C. S., Zhou, J., and Anderson, B. E.: Aircraft profiles of aerosol microphysics and optical properties over North America: Aerosol optical depth and its association with $\mathrm{PM}_{2.5}$ and water uptake, J. Geophys. Res., 112, D12S20, doi:10.1029/2006JD007918, 2007.

Shinozuka, Y., Redemann, J., Livingston, J. M., Russell, P. B., Clarke, A. D., Howell, S. G., Freitag, S., O’Neill, N. T., Reid, E. A., Johnson, R., Ramachandran, S., McNaughton, C. S., Kapustin, V. N., Brekhovskikh, V., Holben, B. N., and McArthur, L. J. B.: Airborne observation of aerosol optical depth during ARCTAS: vertical profiles, inter-comparison and fine-mode fraction, Atmos. Chem. Phys., 11, 3673-3688, doi:10.5194/acp-11-36732011, 2011.

Wang, J. and Christopher, S. A.: Intercomparison between satellitederived aerosol optical thickness and $\mathrm{PM}_{2.5}$ mass: Implications for air quality studies, Geophys. Res. Lett., 30, 2095, doi:2010.1029/2003GL018174, 2003. 